\title{
In Vivo Handling of Soluble Complement Fixing Ab/dsDNA Immune Complexes in Chimpanzees
}

\author{
Robert P. Kimberly, ${ }^{\star}$ Jeffrey C. Edberg, ${ }^{*}$ Louis T. Merriam, ${ }^{*}$ Sarah B. Clarkson, ${ }^{\star}$ Jay C. Unkeless, ${ }^{5}$ and Ronald P. Taylor" \\ ${ }^{*}$ The Hospital for Special Surgery, Cornell University Medical College, New York 10021; ${ }^{\ddagger}$ Rosalind Russell Arthritis Research \\ Laboratory, San Francisco General Hospital, San Francisco, California 94110; § The Department of Biochemistry, \\ Mount Sinai School of Medicine, New York 10029; "The Department of Biochemistry, \\ University of Virginia School of Medicine, Charlottesville, Virginia 22908
}

\begin{abstract}
We used soluble, C-fixing antibody/dsDNA IC to investigate immune complex (IC) handling and erythrocyte (E)-to-phagocyte transfer in chimpanzees. IC bound efficiently to chimpanzee $E$ in vitro and showed minimal release with further in vitro incubation in the presence of serum in EDTA $(\leq 15 \%$ within 1 h). These IC also bound rapidly to $E$ in vivo (70-80\% binding within $1 \mathrm{~min}$ ) and did not show detectable release from $E$ in the peripheral circulation after infusion in vivo ( $\leq 2 \%$ within $1 \mathrm{~h}$ ). Despite such slow $C$-mediated release of IC from $E$, IC were rapidly stripped from $\mathrm{E}$ by the mononuclear phagocyte system $\left(T_{50}\right.$ for $E-I C_{1500}=5 \mathrm{~min}$ ) without sequestration of $E$. Treatment of the chimpanzees with the anti-FcrRIII MAb 3 G8 impaired the clearance of infused IC. This effect was most evident on the fraction of $\mathrm{IC}_{500}$ which did not bind to $E$ and which presumably had captured less $\mathrm{C3b}$ (pre-MAb $3 G 8 \mathrm{~T}_{50}$ : $45 \mathrm{~min}$ vs. post-MAb $\left.3 G 8 \mathrm{~T}_{50}: 180 \mathrm{~min}\right)$. With $\mathrm{IC}$ bound in vitro to $E$ before infusion, anti-FcrRIII MAb treatment led to significant amounts of non-E bound IC detectable in the circulation. Thus, the anti-FcrRIII MAb appeared to interfere with the ability of fixed tissue mononuclear phagocytes to take up/or retain $\mathrm{IC}$ after their release from $\mathrm{E}$. Both rapid stripping of IC from $E$, despite slow complement-mediated release of IC from $E$ in the peripheral circulation, and blockade of IC clearance with anti-FcrRIII MAb indicate that the interaction of IC with the fixed tissue phagocyte involves qualitatively different mechanisms than the interaction of IC with $\mathrm{E}$. Fc $\gamma$ receptors appear to play an important role in the transfer and retention of IC by the phagocyte.
\end{abstract}

\section{Introduction}

Altered handling of immune complexes (IC) ${ }^{1}$ is an important factor in the development of IC mediated disease. In experimental animals, saturation of clearance mechanisms or pro-

Address reprint requests to Dr. Kimberly, The Hospital for Special Surgery, Cornell University Medical College, 535 East 70th Street, New York, NY 10021.

Received for publication 15 February 1989 and in revised form 4 May 1989.

1. Abbreviations used in this paper: CR1, complement receptor type 1; E-IC, erythrocyte bound Ab/dsDNA immune complexes; Fc $\gamma \mathrm{R}$, receptor for the Fc region of IgG; IC, immune complex; $\mathrm{IC}_{1,500}$, immune complexes made with dsDNA of 1,500 base pairs; IC $_{500}$, immune complexes made with dsDNA of 500 base pairs; MPS, mononuclear phagocytic system; $\mathbf{M} \phi$, phagocyte; SAS, saturated ammonium sulfate.

J. Clin. Invest.

(c) The American Society for Clinical Investigation, Inc.

0021-9738/89/09/0962/09 \$2.00

Volume 84, September 1989, 962-970 longation of IC circulation times by various techniques can lead to increased IC deposition in target organs (1-6). The mononuclear phagocyte system (MPS) of liver and spleen provides the primary mechanism for IC disposal (5-9). Circulating IC are removed by binding to receptors for the Fc portion of $\mathrm{IgG}$ and receptors for $\mathrm{C} 3$ fragments on the fixed tissue mononuclear phagocytes of this system $(5,8-12)$. Recent work by Hebert (13-16) and others (17-20), however, has emphasized the importance of complement (C) receptor type 1 (CR1)-mediated binding of circulating $\mathrm{C}$-fixing IC to human and nonhuman primate erythrocytes $(\mathrm{E})$. These observations suggest that E can act as a "buffer," which can bind C-fixing IC by way of CR 1 and may decrease the probability of deposition of these IC in target tissues $(21,22)$.

CR1-mediated $\mathrm{E}$ binding in primates (and a comparable platelet binding reaction in nonprimates [23-25]) leads to the possibility that $\mathrm{E}$ may serve not only as a buffer by partitioning circulating IC to an E-bound pool but also as a delivery system, or "shuttle", which presents IC to the MPS for removal (26). From the perspective of an "erythrocyte shuttle", several questions become evident: $(a)$ what are the determinants of the efficiency of binding to $\mathrm{E} ;(b)$ is binding to an $\mathrm{E}$ a prerequisite for removal by the MPS; $(c)$ are the fates of E-bound IC and non-E bound IC different; and $(d)$ what are the mechanisms of transfer of IC from E to the MPS? Some information regarding these questions is available. For example, among the determinants of IC binding to $E$ via $C R 1$, the ability to fix $C$, the amount of $\mathrm{C} 3 \mathrm{~b}$ capture and the spatial organization of the captured $\mathrm{C} 3 \mathrm{~b}$ are important $(25,27)$. Binding to $\mathrm{E}$ is not a prerequisite for efficient handling by the MPS $(14,25,28)$. Both model IC with rapid C-mediated release from $\mathrm{E}$ (tetanus/anti-tetanus toxoid and BSA/anti-BSA in vivo [13, 18] and in vitro $[29,30])$ and model IC with slow C-mediated release from $\mathrm{E}$ (Ab/dsDNA in vivo [24, 25] and in vitro [31]) are cleared quickly by the MPS. These observations suggest that $\mathrm{E}$ binding may not fundamentally affect the rate of removal of IC by the MPS and that other properties of the IC or factors in the MPS must be significant.

To investigate the properties of the immune adherence reaction in IC handling in primates and to probe the nature of the E-to-phagocyte $(\mathbf{M} \phi)$ transfer mechanism, we performed a series of model IC infusion studies in chimpanzees. As a model IC system we used Ab/dsDNA IC because this antigen-antibody system is relevant to autoimmune disease $(32,33)$, these model IC fix C efficiently and bind to E CR1 (34-36), and their slow release from $\mathrm{E}$ allows for direct investigation of potential $\mathrm{E}$ sequestration during the IC transfer process. In addition to conventional clearance studies, we used anti-Fc $\gamma$ receptor $\mathrm{MAb}$ infusions to probe the role of $\mathrm{Fc} \gamma$ receptors in the removal of soluble IC from the circulation by the MPS. Our data indicate that $\mathrm{C}$-fixing Ab/dsDNA IC bind rapidly to primate $\mathrm{E}$, that IC are transferred to $\mathrm{M} \phi$ without sequestration 
of $E$ or apparent release of IC into the circulation, and that an Fc $\gamma R$ on the M $\phi$ participates in the uptake of IC. These data, demonstrating that the transfer mechanism is much faster than C (Factor I) mediated spontaneous release of IC from $\mathrm{E}$ and that Fc $\gamma$ RIII blockade alters IC uptake, indicate that the interaction of IC with fixed tissue phagocytes involves qualitatively different mechanisms than the interaction of IC with $\mathrm{E}$.

\section{Methods}

Animals. Healthy adult chimpanzees (Pan troglodytes), maintained at the New York University Laboratory of Experimental Medicine and Surgery in Primates (LEMSIP), Tuxedo Park, NY, were used to study the handling of $\mathrm{Ab} / \mathrm{dsDNA}$ IC. Previous work has demonstrated that neutrophils from chimpanzee, but not from seven other nonhuman primate species, bind MAb 3G8 (12), which recognizes Fc $\gamma$ RIII in humans (37). All in vivo experimental procedures were performed at LEMSIP with animals maintained under light ketamine anesthesia. All protocols were approved by the Institutional Animal Care and Use Committee of LEMSIP.

Preparation of antibodies. The 7S IgG fraction of an SLE plasma (plasma Ma), which contains high titer nonprecipitating anti-dsDNA antibodies, was prepared as previously described $(25,35)$. The IgG anti-dsDNA antibodies isolated from this plasma form soluble, C-fixing IC with dsDNA that bind to CR1 on human $E(31,36)$. The biophysical and immunological properties of these IC have been extensively characterized both in vitro and in vivo in a number of animal systems $(24,25,27,28,31,34-36)$.

3G8, a murine IgG1 MAb recognizing human Fc $\gamma$ RIII, was prepared by Damon Biotechnology (Needham Heights, MA). MOPC 21, a murine IgG1 myeloma protein, was prepared as previously described (12). Fab fragments were prepared by digestion with papain-Sepharose (Sigma Chemical Co., St. Louis, MO) and were purified by passage over protein A-Sepharose (Pharmacia Fine Chemicals, Piscataway, $\mathrm{NJ}$ ) at $\mathrm{pH} 8.3$ and by molecular sieve chromatography with a column of TSK 3000 (LKB Instruments, Inc., Rockville, MD). Proteins were $>95 \%$ pure, and Fab fragments contained no detectable heavy chains, as judged by silver stain of SDS-PAGE analytical gels. Preparations used for infusions were sterile and contained $<0.25 \mathrm{ng}$ endotoxin $/ \mathrm{mg}$ of total protein, as determined by the Limulus amebocyte assay (Associates of Cape Cod, Woods Hole, MA).

Preparation of radiolabeled $d s D N A$. Iodinated dsDNA was prepared and characterized before each experiment as previously described $(24,25)$. Briefly, PM2 dsDNA, either intact $(9,000 \mathrm{bp})$ or sonicated (800 bp), was radiolabeled with ${ }^{125} \mathrm{I}$-dCTP (New England Nuclear, Boston, MA) by nick translation. The sizes of the resulting ${ }^{125}$ I-labeled dsDNA preparations were $1,500 \pm 200$ bp ("large dsDNA") and $500 \pm 100$ bp ("small dsDNA"), respectively, as determined by 3.5\% PAGE. The radiolabeled preparations ranged from 1,000 to $2,000 \mathrm{cpm} / \mathrm{ng}$ sp act. The ${ }^{125} \mathrm{I}$-dsDNA preparations were $80-92 \%$ double-stranded as assessed by S1 nuclease digestion (Bethesda Research Laboratories, Gaithersburg, MD) and > 95\% precipitable in 5\% TCA.

Preparation and characterization of soluble immune complexes. The 7S IgG anti-dsDNA was titered with each DNA preparation to determine the amount of antibody required for maximal C-mediated binding (34). These IC give $>90 \%$ binding in the Farr assay (38). To insure that the dsDNA was saturated with anti-DNA antibodies, soluble IC for the in vivo experiments were prepared at a two- to threefold higher $\mathrm{Ab} / \mathrm{dsDNA}$ ratio $(27,35)$. IC made with dsDNA of $500 \mathrm{bp}$ are typically $50-100 \mathrm{~S}$ in size (34).

For experiments with IC released in vitro from chimpanzee $\mathrm{E}$ (see below), the relative sizes of the dsDNA antigen in different IC preparations were checked by submarine gel electrophoresis in $1 \%$ low endoosmotic agarose. Gels were visualized directly under ultraviolet light and then autoradiographed with Kodak XAR film. No differences in the size of the dsDNA antigen from the initial IC preparation relative to that from the released preparation could be detected.
Preparation of erythrocytes for in vitro and in vivo use. $\mathrm{E}$, isolated from heparinized whole blood, were washed twice with PBS-10 mM EDTA and three times with PBS containing $0.15 \mathrm{mM} \mathrm{CaCl}_{2}$ and 0.5 $\mathrm{mM} \mathrm{MgCl} 2\left(\mathrm{PBS}^{+2}\right)$. Chromium labeled $\mathrm{E}$ were prepared by incubating an aliquot of $25 \%$ (vol/vol) autologous $\mathrm{E}$ with $0.5 \mathrm{mCi}$ of ${ }^{51} \mathrm{Cr}$ for 30 $\min$ at $37^{\circ} \mathrm{C}$. The radiolabeled $\mathrm{E}$ were subsequently washed three times and resuspended at a concentration of $25 \%$ in $\mathrm{PBS}^{+2}$.

Immune complex binding to primate erythrocytes in vitro. For quantitative binding of IC to chimpanzee $\mathrm{E}$ or human $\mathrm{E}$ in the presence of autologous serum $C$, washed $E$ were incubated with subsaturating concentrations of freshly prepared IC for $20 \mathrm{~min}$ at $37^{\circ} \mathrm{C} \mathrm{(34).}$ This procedure typically yielded $>85 \%$ bound and $10-20$ IC per E. After one wash with $\mathrm{PBS}^{+2}$ to remove unbound IC and the addition of fresh serum in EDTA (as a source of C), the release reaction was assessed by the time-dependent appearance of unbound IC in the supernatant (39). To assess possible $C$-independent binding to chimpanzee $\mathrm{E}$, aliquots of $\mathrm{E}, 7 \mathrm{~S}$ anti-DNA IgG and labeled dsDNA were incubated with heat-inactivated serum. Negligible binding $(<10 \%)$ occurred under these conditions. Similarly, ${ }^{125} \mathrm{I}$-dsDNA mixed with fresh serum $C$ did not bind to $E$ in the absence of antibody.

Experimental protocols for handling of soluble IC. For each in vivo experiment IC were freshly prepared according to one of four protocols from titered stocks of anti-dsDNA IgG and radiolabeled dsDNA. (a) For direct in vivo infusions of soluble $\mathrm{C}$-fixing IC, predetermined amounts of $7 \mathrm{~S} \mathrm{IgG} \mathrm{anti-dsDNA}$ and ${ }^{125} \mathrm{I}$-dsDNA were mixed and incubated for $1 \mathrm{~h}$ at $37^{\circ} \mathrm{C}$ just before intravenous injection. (b) For IC bound in vitro to autologous $\mathrm{E}$, freshly prepared soluble IC were incubated for $20 \mathrm{~min}$ at $37^{\circ} \mathrm{C}$ with a $25 \%$ suspension of ${ }^{51} \mathrm{Cr}$-labeled chimpanzee $E$ and fresh autologous serum $C$. After one wash with PBS, these "IC-loaded" E were injected immediately. (c) To obtain "released complexes" an aliquot of "IC-loaded" E was further incubated with fresh autologous serum as a $\mathrm{C}$ source and actively mixed for 3-4 $\mathrm{h}$ at $37^{\circ} \mathrm{C}$. The resultant supernatant, containing the released IC, was harvested and injected intravenously. Under these conditions this procedure yielded $40-60 \%$ release of IC from E. (d) Finally, IC were prepared in vitro to contain large amounts of human $\mathrm{C} 3 \mathrm{~d}, \mathrm{~g}$ fragments ("partial d,g IC") as previously described (31). $\mathrm{Ab} /{ }^{3} \mathrm{H}$-dsDNA IC were opsonized with human $\mathrm{C}$ and allowed to bind to human $\mathrm{E}$. The IC were then released from the $\mathrm{E}$ by overnight incubation in serum at $37^{\circ} \mathrm{C}$. These released IC (containing C3d,g) were treated with DNAse and then 50\% SAS to recover the C3d,g-containing anti-dsDNA IgG. These Ab formed IC with fresh dsDNA (as detected in the Farr assay) that did not bind significantly to human $E$ in the presence or absence of fresh human $C$ (typically $<25 \%$ ). This IgG preparation was then used according to protocol a.

The IC were injected into an antecubital vein in $<5 \mathrm{~s}$. Blood samples $(5.0 \mathrm{ml})$ were then drawn from the opposite arm every $30 \mathrm{~s}$ in initial experiments (every minute in later experiments) for the first 3 min, then at $5,7.5,10,20,30$, and $60 \mathrm{~min}$. Saline or MAb $3 G 8(0.8$ $\mathrm{mg} / \mathrm{kg}$ ) was then infused over $30 \mathrm{~min}$ and a second clearance study with an identical protocol was performed. Initial experiments indicated that the first study did not alter subsequent clearance studies (Fig. $5 \mathrm{~A}$; reference 12 ).

Each 5.0-ml sample of blood was immediately heparinized, put on wet ice, and centrifuged at $2,000 \mathrm{rpm}$ for $4 \mathrm{~min}$. The cell pellet, containing both $\mathrm{E}$ and leukocytes, was rapidly resuspended in iced PBS, centrifuged again, and separated from the supernatant. This processing of the pellet was complete within $10 \mathrm{~min}$. As a control for time-dependent release of IC from $\mathrm{E}$ after phlebotomy but before completed sample processing, selected duplicate specimens were set aside for $\mathbf{3 0}$ min on wet ice and then processed in the usual fashion. No detectable release of the bound IC was observed. Finally, selected blood specimens were separated on single density Percoll to confirm that the IC were bound to the $E(13,19)$.

The supernatant harvested from the washed cell pellet was combined with the initial iced plasma supernatant for each sample. Aliquots $(1.0 \mathrm{ml})$ were mixed with one-half volume of $15 \%$ TCA at room temperature to precipitate intact dsDNA (immune complexed or free). 
Saturated ammonium sulfate (SAS) was added to a second $1.0-\mathrm{ml}$ aliquot for a final concentration of $40 \% \mathrm{vol} / \mathrm{vol}$ on wet ice to precipitate immune complexed ${ }^{125} \mathrm{I}$-dsDNA. After centrifugation at 5,000 rpm for $20 \mathrm{~min}$, the supernatants and precipitates were harvested and counted separately. A third measured aliquot of the plasma plus wash supernatant was saved and counted directly.

Experimental protocol for handling of IgG-opsonized erythrocytes (12). Chimpanzee E were chromium labeled and sensitized with an amount of chimpanzee anti-AcBcDc antiserum sufficient to yield 20,000 molecules of IgG per E. After intravenous injection of opsonized cells, blood samples were obtained from the opposite arm at 3, 5, $15,30,60,90$, and $120 \mathrm{~min}$. A second study with freshly opsonized $\mathrm{E}$ was performed after infusion of MAb 3G8.

Data analysis in the soluble IC experiments. For each blood sample the counts for each fraction (cell pellet; TCA supernatant and TCA pellet; SAS supernatant and SAS pellet; unaltered plasma) were combined to derive total sample counts. The sum of both TCA fractions, both SAS fractions and the unaltered plasma fraction was designated "non-E bound"; the cell pellet was designated "erythrocyte bound" since Percoll density gradient analysis indicated that essentially all counts were associated with the $\mathrm{E}$ fraction. The non-E bound but TCA precipitable IC were calculated by the following formula: [TCA pellet/ (TCA supernatant + TCA pellet)] $\times$ total non-E bound counts. The same calculation was used to determine the SAS precipitable non-E bound IC. The total TCA (or SAS) precipitable counts were defined as the sum of both the TCA (SAS) precipitable non-E bound counts and the $E$ bound counts; this calculation assumes that all $E$ bound counts would be precipitable in solution $(24,25)$. For the double label experiments, absolute counts per minute were corrected for spectral overlap of the two isotopes.

For clearance studies, each curve represents the mean $( \pm S D)$ of all animals for each experimental condition. The clearance curves, both before and after MAb $3 G 8$ infusion, were analyzed for the time required for the clearance of 50 and $75 \%$ of the $E$ bound (or non-E bound TCA precipitable) counts $\left(T_{50}\right.$ and $T_{75}$, respectively) relative to the counts present at $1 \mathrm{~min}$ in the appropriate fraction. In addition, we calculated the recovery of counts in the circulation based on the total counts infused and on the estimated blood volume of the animal. Typically, at $1 \mathrm{~min}, 75-85 \%$ of the total infused counts were present in the circulation.

\section{Results}

\section{Antibody/dsDNA complexes in the chimpanzee model system}

Binding of IC to chimpanzee erythrocytes in vitro. Human $7 \mathrm{~S}$ IgG anti-DNA/dsDNA IC made with large DNA $(\sim 1,500$ bp $\left.\left[\mathrm{IC}_{1,500}\right]\right)$ bind efficiently to human $\mathrm{E}$ in a C-dependent fashion (31, 34-36). Similarly, $>80 \%$ of model IC made with larger DNA ( 3,000 bp) bind $\mathrm{E}$ from rhesus monkey when assayed in vitro and tested in vivo (19). To confirm C-mediated IC binding to chimpanzee E, IC made with ${ }^{125}$ I-labeled dsDNA (both $\mathrm{IC}_{1,500}$ and IC prepared with small dsDNA of $\sim 500 \mathrm{bp}$ $\left.\left[\mathrm{IC}_{500}\right]\right)$ and ${ }^{3} \mathrm{H}$-labeled intact PM2 dsDNA were incubated with autologous serum as a source of $C$ and an excess of $E$ for $20 \mathrm{~min}$ at $37^{\circ} \mathrm{C}$. Efficient binding to chimpanzee $\mathrm{E}$ was evident for all three dsDNA preparations (Table I). Only $15 \%$ of the IC were released from chimpanzee $\mathrm{E}$ within $60 \mathrm{~min}$ after the addition of fresh $C$ in EDTA. These data indicate that IC containing large dsDNA IC bind efficiently to chimpanzee $\mathrm{E}$ in vitro and in addition that the in vitro C-mediated release reaction for these large IC from chimpanzee $\mathrm{E}$ is slower than it is for human $\mathrm{E}$.

Partitioning of soluble IC to erythrocytes in vivo. Large, soluble antibody/dsDNA IC $\left(\mathrm{IC}_{1,500}\right)$ showed rapid binding to
Table I. Binding of Ab/dsDNA IC to and Release from Human and Chimpanzee E In Vitro*

\begin{tabular}{|c|c|c|c|c|c|c|}
\hline \multirow[b]{3}{*}{$\begin{array}{l}\text { Size of } \\
\text { dsDNA }\end{array}$} & \multicolumn{3}{|c|}{ Human E } & \multicolumn{3}{|c|}{ Chimpanzee E } \\
\hline & \multirow[b]{2}{*}{$\%$ Bound } & \multicolumn{2}{|c|}{$\%$ Release ${ }^{*}$} & \multirow[b]{2}{*}{ \% Bound } & \multicolumn{2}{|c|}{$\%$ Release $^{*}$} \\
\hline & & Buffer & $\begin{array}{l}\text { Serum/ } \\
\text { EDTA }\end{array}$ & & Buffer & $\begin{array}{c}\text { Serum/ } \\
\text { EDTA }\end{array}$ \\
\hline $9000 \mathrm{bp}$ & $85 \%$ & $15 \%$ & $90 \%$ & $85 \%$ & $<5 \%$ & $15 \%$ \\
\hline $1500 \mathrm{bp}$ & $45 \%$ & $\mathrm{ND}^{\S}$ & ND & $85 \%$ & ND & ND \\
\hline $500 \mathrm{bp}$ & $<10 \%$ & ND & ND & $50 \%$ & $5 \%$ & $15 \%$ \\
\hline
\end{tabular}

* Results are representative of experiments performed on two or more different donors for both chimps and humans. SD for values are $\pm 5 \%$. In all cases, homologous serum was used for opsonization and release.

₹ Percent release of IC (after maximal E binding) upon the addition of fresh autologous serum in EDTA (or buffer) for $1 \mathrm{~h}$ at $37^{\circ} \mathrm{C}$ as described in Methods. Slightly more release of IC from chimpanzee $\mathrm{E}$ was evident at $2 \mathrm{~h}$.

$\S$ Not done.

the chimpanzee $\mathrm{E}$ after intravenous infusion. More than $50 \%$ of circulating IC were bound within $15 \mathrm{~s}$ and $\sim 70 \%$ were bound by 1 min, whereas native DNA (both $\sim 1,500 \mathrm{bp}$ and $\sim 500 \mathrm{bp}$ ) showed minimal binding $(<6 \%)$ to $\mathrm{E}$ (Fig. 1). These findings are consistent with observations of rapid binding to $\mathrm{E}$ of similar $\mathrm{Ab} / \mathrm{dsDNA} \mathrm{IC}$ in baboons (16) and in rhesus monkeys (19), of very large anti-BSA/BSA IC in baboons (13), and of tetanus/antitetanus toxoid IC in humans (18).

In attempts to generate IC that would not bind to the $\mathrm{E}$ in vivo, we decreased the size of the dsDNA (34), used IC harvested from $E$ after serum-mediated release (31), and generated IC partially opsonized with the human $\mathrm{C}$ degradation

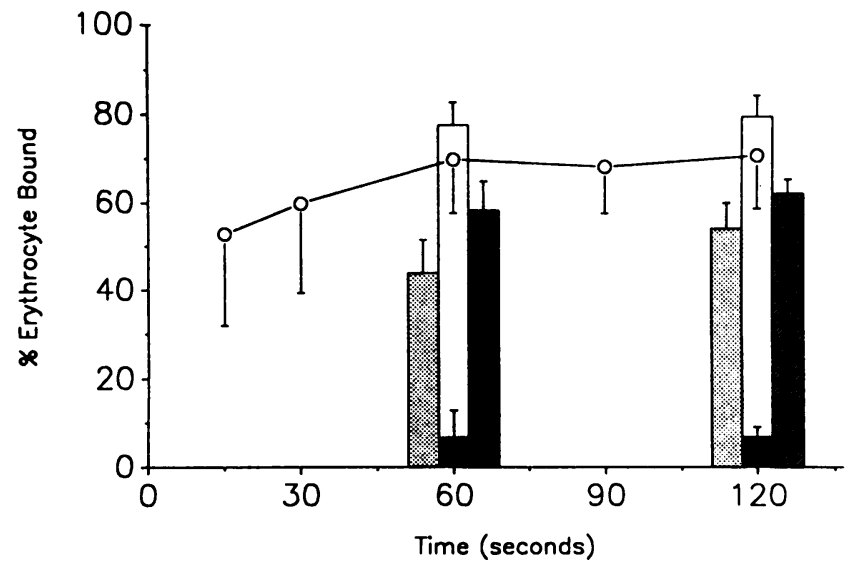

Figure 1. Binding of antibody $/{ }^{125} \mathrm{I}$-dsDNA IC to $\mathrm{E}$ in vivo. The mean percent $( \pm S D)$ of $I C$ bound to $E$ is shown at several different time points. $\mathrm{IC}_{1,500},(0)(n=4$ animals), showed peak binding at $60 \mathrm{~s}$. $\mathrm{IC}_{500}(n=8 ; \square)$, serum released $\mathrm{IC}_{1,500}(n=2 ;$; $)$, partial-d, $\mathrm{gIC}_{1,500}(n$ $=4 ; \square)$ and free dsDNA (both $1,500 \mathrm{bp}$ and $500 \mathrm{bp})(n=6 ; \square)$ values are shown for 60 and $120 \mathrm{~s}$ (see Methods for preparation of ICs). 60 -s values were within $5 \%$ of absolute peak values for all IC except the partial-d,g IC S00 $_{50}$ which showed a difference between 60 - and 120 -s values $(44.0 \pm 7.7$ vs. $54.1 \pm 5.8 \% ; P<0.01)$ and a peak percent E binding $(60.2 \%)$ at $\sim 7.5 \mathrm{~min}$. 


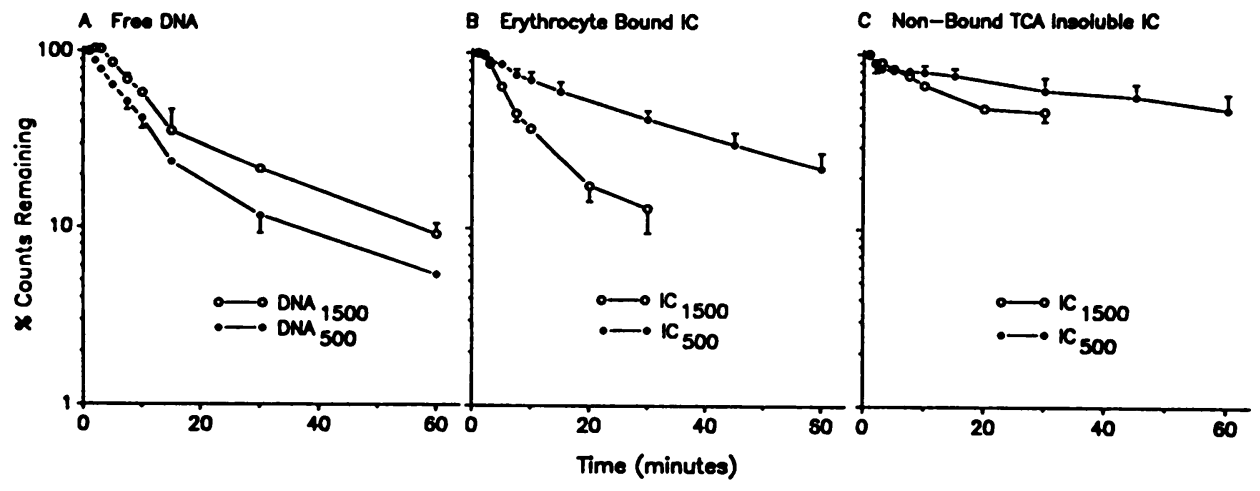

Figure 2. Clearance of Free DNA and antibody/dsDNA IC. The clearances of TCA precipitable ${ }^{125} \mathrm{I}$ dsDNA $(A)$, in vivo E-bound IC $(B)$ and TCA precipitable IC in the non-E bound plasma fraction $(C)$ are represented as the mean percent of counts remaining relative to counts determined at one min. For $\operatorname{dsDNA}_{1.500}(n=4$ animals) and $\operatorname{dsDNA}_{500}(n=2)$, TCA precipitable counts (intact dsDNA) comprised $>90 \%$ of all counts; there was no increase in the percentage of soluble counts over the course of the experiment. With both $\mathrm{IC}_{1,500}(n=2)$ and $\mathrm{IC}_{500}(n=4)$ there was a strong correlation between values for TCA precipitable (immune complexed or free) and SAS precipitable counts (immune complexed $\left.{ }^{125} \mathrm{I}-\mathrm{dsDNA}\right)$ in the non-E bound fraction $(r=0.97$ and $r=0.95$, respectively) and only the TCA precipitable counts are shown for simplicity. TCA precipitable non-E bound counts represented $24.3 \pm 9.5 \%$ (mean \pm SD) of total counts at $1 \mathrm{~min}$ while TCA nonprecipitable, non-E bound counts were $6.1 \pm 1.9 \%$ of that total. At 30 min these values were $15.2 \pm 4.5 \%$ and $5.8 \pm 1.9 \%$ of the total counts at $1 \mathrm{~min}$, respectively; at $60 \mathrm{~min}$ they were $9.1 \pm 3.0 \%$ and $5.6 \pm 1.8 \%$, respectively.

product C3d,g (partial-d,g IC; [31]). The $\mathrm{IC}_{500}$ demonstrated binding to the $\mathrm{E}$ comparable to the IC prepared with the larger dsDNA (Fig. 1). Similarly, IC released in serum and the partial-d,g IC became opsonized with $\mathrm{C}$ in vivo as they were $62 \%$ and $54 \%$ E-bound, respectively, 2 min after infusion. The binding of these latter two IC preparations to $E$ in vivo is somewhat in contrast to the in vitro human model. Preliminary evidence with anti-CR1 MAb E11 suggests that chimpanzee $E$ have two to three times more $C R 1$ sites than human $\mathrm{E}$ and that this may account for the higher IC binding. Since all of these IC were able to bind to chimpanzee $\mathrm{E}$ in vivo, we emphasized the $\mathrm{IC}_{500}$ for soluble IC infusions with concomitant anti-Fc $\gamma$ RIII MAb administration. Both the released IC and the partial-d,g IC probably contain larger quantities of bound $\mathrm{C} 3$ degradation products which could influence IC removal by the MPS by other C receptors (CR2, CR3, or CR4 [40]).

Clearance of soluble, infused immune complexes. To test the in vivo behavior of both bound and non-E bound IC we infused several different types of soluble Ab/dsDNA IC. Initial experiments with free $1,500 \mathrm{bp}$ and $500 \mathrm{bp}$ dsDNA demonstrated that free DNA does not bind to E (Fig. 1) and is cleared from the circulation with an initial half-time of 10-15 min (Fig. $2 \mathrm{~A}$ ). This clearance rate is substantially slower than that found in nonprimates (half-time of 1-2 $\mathrm{min} ;[19,25]$ ) but is comparable to that found in other primates $(16,19)$. Formation of IC with dsDNA altered the handling of the DNA. Most $\mathrm{IC}_{1,500}$ became bound to $\mathrm{E}$ in vivo and were cleared more rapidly than free DNA alone while non E-bound IC were cleared more slowly than free DNA alone. $\mathrm{IC}_{500}$ showed slower clearance, whether E-bound or non-E bound, than free DNA (Fig. 2, $B$ and $C$ ). Interestingly, the clearance rate of E-bound $\mathrm{IC}_{1,500}$ was slower when soluble $\mathrm{IC}_{1,500}$ was infused directly than when $\mathrm{IC}_{1,500}$ was bound to $\mathrm{E}$ in vitro before infusion (see Fig. $2 \mathrm{~B}$ and Fig. $3 \mathrm{~A}$ ). This observation suggests that loading of $E$ with IC may continue over time after soluble IC infusion and lead to an apparently slower clearance rate for Ebound IC.
A Enthrogte Bound $\mathrm{CC}$

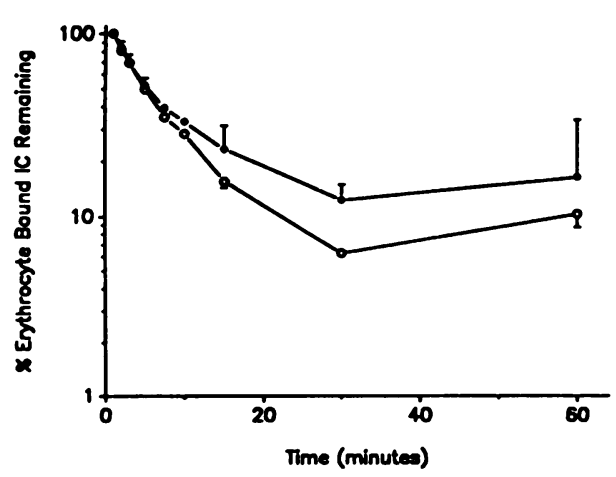

B Non-Bound TCA mooluble IC

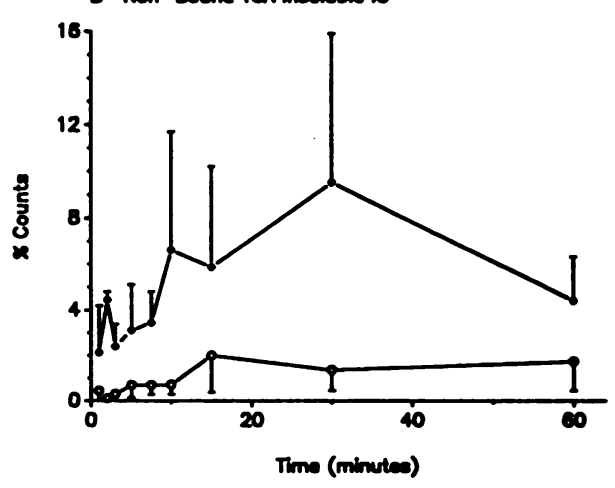

Figure 3. Handling of $\mathrm{IC}_{1,500}$ prebound to $\mathrm{E}$ in vitro. $(A)$ The clearance of $\mathrm{IC}_{1.500}$ prebound to $E$ in vitro. The baseline clearance is shown with open circles while the clearance after infusion of antiFc $\gamma$ RIII MAb is shown by the closed circles $(n=2)$. Data are presented as the percent of counts remaining relative to one min (mean $\pm \mathrm{SD}$ ). (B) The appearance de novo of TCA precipitable non-E bound counts in the peripheral circulation under each condition (baseline in open circles [ $n=4]$; after anti-Fc $\gamma$ RIII MAb in closed circles $[n=2])$ is represented.

Values are calculated as a percentage of total counts at 1 min (mean \pm SD). SAS precipitable non-E bound counts show an analogous pattern with a high correlation to the TCA results $(r=0.79)$. In the absence of anti-Fc $\gamma$ RIII, TCA nonprecipitable, non-E bound counts were $\leq 1 \%$ of total $1 \mathrm{~min}$ counts during the first $10 \mathrm{~min}$ and increased to $4-5 \%$ by $30-60 \mathrm{~min}$. In contrast, after anti-Fc $\gamma \mathrm{RIII}$ infusion, there was no increase above baseline in the TCA nonprecipitable fraction throughout the $60 \mathrm{~min}$ of study. 
Disposition of in vitro erythrocyte bound antibody/dsDNA immune complexes. In several IC model systems, IC release rapidly from $\mathrm{E}$ after initial $\mathrm{C}$-mediated binding. Both antiBSA/BSA and tetanus/antitetanus toxoid IC show a rapid return to fluid phase in vitro $(29,30)$. This rapid release has also been sought and demonstrated in vivo with tetanus/antitetanus toxoid IC (18). Ab/dsDNA IC do not show rapid release in vitro (Table I), and therefore, experiments were designed to test for the occurrence of the release reaction in vivo. IC were bound to autologous $\mathrm{E}$ in vitro and these IC-loaded $\mathrm{E}$ alone were infused (Fig. $3 \mathrm{~A}$, open circles). No detectable release of IC into a non-E bound fraction was found in the circulation ( $<1 \%$ during the first $10 \mathrm{~min}$ and $<2 \%$ over $1 \mathrm{~h}$; Fig. $3 B$, open circles).

Given the lack of detectable release of $A b / d s D N A$ IC from $\mathrm{E}$ into the circulation, we tested the possibility that these ICopsonized E would be sequestered by the MPS like E opsonized with anti-E IgG (12). Previous investigators attempting to address this question have looked for a change in the total body $\mathrm{E}$ mass rather than at the specific fate of those $\mathrm{E}$ opsonized with IC (13). Using double radiolabel techniques we examined the fate of the ${ }^{51} \mathrm{Cr}$-labeled $\mathrm{E}$ opsonized with 10-20 ${ }^{125}$ I-labeled IC per E. Fig. 4 clearly demonstrates that the ${ }^{51} \mathrm{Cr}$ labeled $\mathrm{E}$ are not removed from the circulation while the ${ }^{125} \mathrm{I}$ labeled IC are rapidly stripped from the E by the MPS.

\section{Role of FcrRIII in immune complex handling}

Fc $\gamma$ RIII (CD16) has been proposed as an Fc $\gamma$ receptor that might participate in IC binding by the MPS. Fc $\gamma$ RIII, defined by MAb 3G8 and other anti-CD16 MAb, is present in the red pulp of human spleen and in human liver sections $(12,41$; Fleit, H. B., personal communication). The CD16 epitope recognized by the MAb $3 \mathrm{G} 8$ is also present in a pattern typical for Kupffer cells in chimpanzee liver sections (12). The role of Fc $\gamma$ RIII in the handling of IgG coated $E$ has been examined in the chimpanzee. Chimpanzee $\mathrm{E}$, opsonized in vitro with anti-

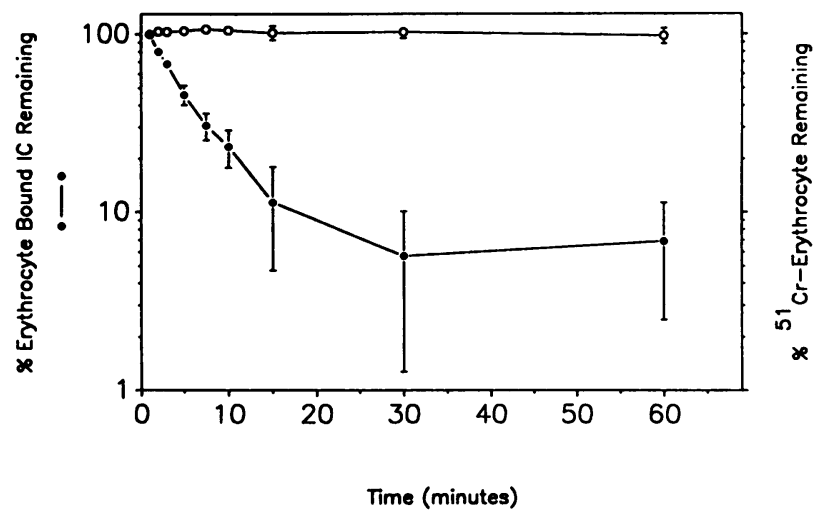

Figure 4. Absence of sequestration of $\mathrm{IC}_{1,500^{-}}$opsonized erythrocytes. ${ }^{51} \mathrm{Cr}$-labeled autologous $\mathrm{E}$, with in vitro prebound antibody/25IdsDNA IC, were infused and the disappearance of counts monitored. Data are presented as the percentage of counts remaining relative to 1 -min values (mean $\pm \mathrm{SD} ; n=4$ ). By $10 \mathrm{~min},>75 \%$ of initially $\mathrm{E}$ bound IC had been "stripped" from E, but $<2 \%$ of these counts were detectable in the total plasma fraction. By $30 \mathrm{~min} 95 \%$ of IC had been stripped from $E$ with $\sim 6 \%$ of counts in the total plasma fraction (1.4\% TCA precipitable and $4.5 \%$ nonprecipitable). No free ${ }^{51} \mathrm{Cr}(<0.2 \%)$ was detectable in the plasma samples. chimpanzee E IgG $(20,000$ molecules of IgG per E), are removed from the circulation with a $T_{50}$ of $70 \mathrm{~min}$ (Fig. $5 \mathrm{D}$, open circles). After infusion of $3 \mathrm{G} 8 \mathrm{IgG}, 0.5$ to $1.0 \mathrm{mg} / \mathrm{ml}$, the clearance of these opsonized $\mathrm{E}$ is significantly prolonged (Fig. $5 \mathrm{D}$, closed circles and reference 12 ). Since these studies indicated that Fc $\gamma$ RIII plays an important role in the uptake of this Fc-mediated probe, we explored the impact of infusions of MAb 3 G8 IgG and Fab on the handling of both $\mathrm{IC}_{1,500}$ prebound to $\mathrm{E}$ in vitro and on $\mathrm{IC}_{500}$ infused as free IC (not prebound).

Effect of anti-Fcy RIII on IC loaded onto $E$ before infusion. $\mathrm{IC}_{1,500}$ bound to chimpanzee $\mathrm{E}$ in vitro were cleared very rapidly after intravenous infusion (initial $\mathrm{T}_{50}$ of $5 \mathrm{~min}$, Figs. $3 \mathrm{~A}$ and 4). Since control studies with infused saline showed that neither ketamine anesthesia nor a prior clearance study prolonged the clearance of additional soluble IC (Fig. $5 \mathrm{~A}$ ), additional studies with $\mathrm{IC}_{1,500}$ prebound to $\mathrm{E}$ in vitro were performed. Infusion of MAb $3 G 8 \mathrm{IgG}, 0.8 \mathrm{mg} / \mathrm{kg}$, did not alter the earliest phase of the curve but did induce a modest impairment of $\mathrm{IC}_{1,500}$ removal after $7.5 \mathrm{~min}$ (Fig. $3 \mathrm{~A}$, closed circles). More striking, however, was the appearance of significant amounts of both circulating non-E bound TCA precipitable and non-E bound SAS precipitable IC after anti-Fc $\gamma$ R MAb infusion. In contrast to the pretreatment experiments (Fig. $3 B$, open circles), clearly measurable free $\mathrm{IC}_{1,500}$ were apparent at every time point after MAb infusion (Fig. $3 \mathrm{~B}$, closed circles). This phenomenon is unlikely to be due to Factor I-mediated release of IC from $\mathrm{E}$ in the periphery (due to prolonged circulation) since it was evident during the first $7.5 \mathrm{~min}$ both when the pre- and posttreatment E-bound IC clearance curves were superimposable. Rather, it would appear that the anti-Fc $\gamma R$ $\mathrm{MAb}$ was interfering with the ability of fixed tissue mononuclear phagocytes to take up and/or retain large, $\mathrm{C}$-fixing $\mathrm{IC}_{1,500}$ after their release from $\mathrm{E}$.

Effect of anti-FcrRIII on infused soluble IC. Infusion of MAb $3 \mathrm{G} 8 \mathrm{IgG}(0.8 \mathrm{mg} / \mathrm{kg})$, or MAb $3 \mathrm{G} 8 \mathrm{Fab}(0.6 \mathrm{mg} / \mathrm{kg}) \mathrm{did}$ not alter the earliest phase of the in vivo E-bound $\mathrm{IC}_{500}$ clearance curve but did induce a modest impairment of removal after $7.5 \mathrm{~min}$ (Fig. $5 \mathrm{~B}$ and $C$, respectively). However, when the non-E bound TCA precipitable $\mathrm{IC}_{500}$ are examined, it can be seen that MAb 3 G8 IgG did produce a large impairment in clearance (Fig. $5 E$ ). When MAb $3 G 8 \mathrm{Fab}$ was infused, no consistent change in the handling of the non-E bound IC fraction was seen (Fig. $5 F$ ). We attribute this observation to unexplained factors since one animal in this experimental pair showed an acceleration of clearance. The other animal showed a significant prolongation in the clearance of the non-E bound IC fraction after MAb $3 \mathrm{G} 8 \mathrm{Fab}$ infusion (pre-MAb $3 \mathrm{G8} \mathrm{T}_{50}$ $=80 \mathrm{~min}$, post $-3 \mathrm{G} 8 \mathrm{~T}_{50}=200 \mathrm{~min}$ ) similar to that induced by MAb 3G8 IgG.

\section{Discussion}

Recent investigations have focused on E CR1 and the role of the immune adherence reaction, originally described in 1953 by Nelson for IC (42), in the handling of circulating IC. A number of studies have carefully documented decreased numbers of CR1 on E from patients with autoimmune disease (43-45) and have shown decreased binding capacity for IC by such $E$ even in the face of large E CR1 excess (46). While directing attention to the potential for $\mathrm{E}$ to partition IC into a bound pool unavailable for tissue deposition, these studies 

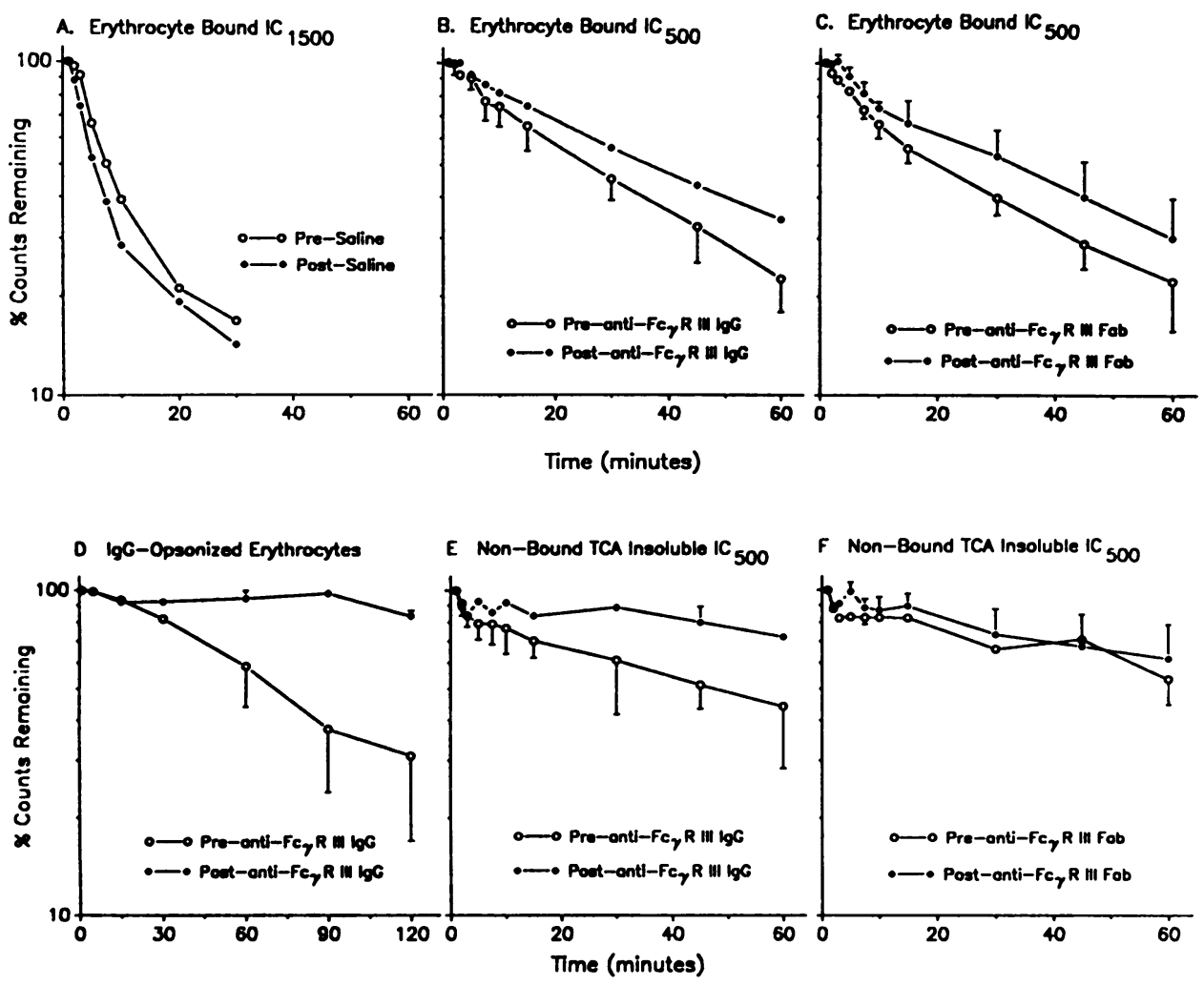

Figure 5. Effect of anti-Fc $\gamma$ RIII MAb on the handling of soluble IC. The effects of anti-Fc $\gamma$ RIII MAb infusions on the handling of several different model IC probes are presented with the data expressed as the percent counts remaining relative to the value for that probe (fraction) at $1 \mathrm{~min}$ (mean $\pm \mathrm{SD})$. (A) The saline control for the paired study design showed no impairment of clearance in study 2 (postsaline) relative to study 1 (presaline; $[n=1]) .(B$ and $C)$ Clearance of $\mathrm{E}$ bound $\mathrm{IC}_{500}$, following intravenous infusion of soluble $\mathrm{IC}_{500}$, was slowed by treatment with both antiFc $\gamma$ RIII MAb IgG and Fab ( $n$ $=2$, each condition). The $T_{50}$ increased from 25 to $36 \mathrm{~min}$ and the $\mathrm{T}_{75}$ from 55 to $78 \mathrm{~min}$ with intact IgG; corresponding values for animals treated with Fab were 21 to 33 min and 54 to $71 \mathrm{~min}$. (D) Clearance of IgG-opsonized $\mathrm{E}$ which was markedly effected by anti-Fc $\gamma$ RIII infusions $(n=2)$. After MAb treatment, the $T_{50}$ was not reached within the 2-h period of observation. $(E$ and $F$ ) Clearance of non-E

bound $\mathrm{IC}_{500}$, after intravenous infusion of soluble $\mathrm{IC}_{500}$, was also slowed by anti-Fc $\gamma \mathrm{RIII}$ MAb IgG and Fab $\left(n=2\right.$, each condition). The $\mathrm{T}_{50}$ increased from $45 \mathrm{~min}$ to $\sim 180 \mathrm{~min}$ with intact $\mathrm{IgG}$. $\mathrm{T}_{75}$ was not reached during the period of observation. In the Fab experiments, one animal showed accelerated clearance after MAb (unlike all other animals) thus leading to a minimal average effect on clearance. The other animal showed a pronounced MAb effect $\left(\mathrm{T}_{50}\right.$ increasing from 80 to $200 \mathrm{~min}$ ).

have not addressed the mechanism of IC uptake by fixed tissue phagocytes. To explore some of the mechanisms involved in IC uptake, both for the transfer of E-bound IC to $\mathrm{M} \phi$ and for the direct uptake of non-E bound IC by $M \phi$, we performed a series of model IC infusion studies in chimpanzees. Our data indicate that transfer from $\mathrm{E}$ to $\mathrm{M} \phi$ proceeds rapidly and much faster than Factor I-mediated release of IC from $E$ both in the circulation and in vitro (Fig. 4, Table I). Blockade of the ligand binding site of Fc $\gamma$ RIII alters the handling of E-bound and non-E bound IC (Fig. 5). Taken together, these data indicate that the interaction of IC and E-IC with fixed tissue phagocytes involves qualitatively different mechanisms than the interaction of IC with E CR1.

The Ab/dsDNA IC were chosen as a model antigen-antibody system because these IC are relevant to autoimmune disease $(32,33)$, they have well-characterized immunochemical properties and their behavior has been studied in human, primate, rabbit, and mouse models $(24,25,27,28,31,34-36)$. These IC fix C efficiently, bind avidly to primate $E$ via CR 1 and release slowly from human $E$ in the presence of Factor $I$ (Table I). These Ab/dsDNA IC are unlike previously studied BSA/anti-BSA and tetanus/antitetanus toxoid IC which show more rapid release from $E$ in the presence of Factor $I(18,29$, $30)$. This important difference in the kinetics of release precludes the use of these latter two model IC systems for the investigation of several critical questions including sequestration of IC-opsonized E by the MPS and retention of IC by M $\phi$ Fc receptors.
Specific examination of the Ab/dsDNA IC model system in chimpanzees revealed in vitro properties analogous to those documented in humans and other animals (Table I). When infused in vivo (Figs. 1 and 2), these model IC behaved similarly to those infused into baboons, rhesus monkeys, rabbits, and mice $(16,19,24,25,28)$. As in the baboon, E-bound $\mathrm{IC}_{1,500}$ were cleared more rapidly in chimpanzee than free dsDNA alone while E-bound $\mathrm{IC}_{500}$ were cleared more slowly than free dsDNA. The higher binding levels of IC to chimpanzee $\mathrm{E}$ (and slower release in vitro) probably reflect a higher density of CR 1 per $E$ as suggested by increased levels of binding of monoclonal anti-CR 1 antibody E11. Efficient uptake of non-E bound IC occurred for both types of IC. Interestingly, free dsDNA alone was cleared much more slowly in chimpanzee (and in other primates $[16,19])$ than in several nonprimate species $(19,25,47)$.

\section{Mechanism of IC transfer from erythrocytes to $M \phi$}

IgG-opsonized $\mathrm{E}$ are sequestered by the MPS in both humans (10) and chimpanzees (12). Given the slow Factor I-mediated release of $\mathrm{Ab} / \mathrm{dsDNA}$ IC from chimpanzee $\mathrm{E}$, we examined whether a similar sequestration of IC-opsonized $\mathrm{E}$ would occur. Previous experimental approaches to this question have been confounded by the use of a model IC probe with rapid release from $\mathrm{E}$ and by measurement of changes in total body $\mathrm{E}$ mass rather than by monitoring of the fate of the specific $E$ loaded with IC. Using double radiolabel techniques and E loaded with IC, we could independently determine the dispo- 


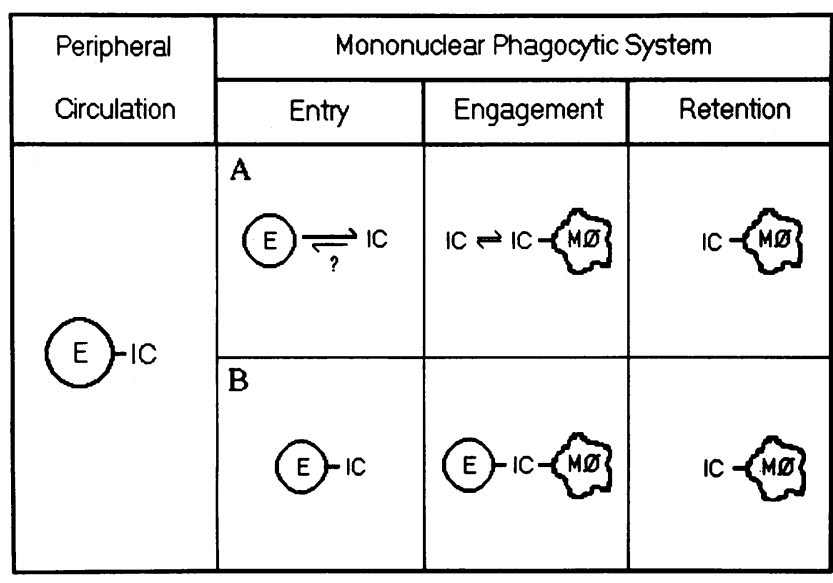

Figure 6. Schematic representation of IC transfer. Two alternative mechanisms for the intrahepatic transfer of IC from $\mathrm{E}$ to $\mathrm{M} \phi$ are presented. In mechanism A IC are released from $\mathrm{E}$ in the hepatic environment before engagement by receptors on the phagocyte. This release could involve a Factor I-mediated process (qualitatively distinct from the periphery), proteolytic cleavage (48) or some other mechanism. In B, E-IC are directly engaged by phagocytes as suggested by Robineaux (55). This alternative implies that release of IC from $\mathrm{E}$ occurs as a secondary consequence of initial engagement of the $E$ by the $\mathbf{M} \phi$.

sition of the model IC and of the $\mathrm{E}$ and demonstrate rapid stripping of the IC from $E$ without sequestration of those $E$ (Fig. 4).

The mechanisms underlying this highly efficient stripping of $\mathrm{E}$, however, remain incompletely defined. It has been proposed that the transfer of IC from $\mathrm{E}$ to $\mathrm{M} \phi$ involves the proteolytic cleavage of the E CR1 $(48,49)$. Such cleavage would have to be very rapid, and unless E CR 1 has a unique susceptibility to such cleavage, CR1 expressed on all cells in the hepatic environment would be susceptible to this proteolytic mechanism. Alternatively, if the mechanisms include high local concentrations of Factor I and more effective cleavage of $\mathrm{C} 3 \mathrm{~b}$, then receptors for $\mathrm{C} 3 \mathrm{~b}(\mathrm{CR} 1)$ on the $\mathrm{M} \phi$ must not play an important role in IC uptake. A much higher density of CR 1 on the $\mathbf{M} \phi$ could be invoked to explain a shift in the reversible C3b-mediated binding from the low density E-CR 1 to much higher density $\mathrm{M} \phi \mathrm{CR} 1$. However, this explanation would appear more appropriate for model IC with faster release reactions in vivo. As demonstrated in Fig. $3 B$ (open circles), this release reaction does not occur with this Ab/dsDNA IC.

Several other receptor systems are available to mediate transfer to and uptake by mononuclear phagocytes. In addition to $C$ receptors for bound $C 3$ degradation products (CR2, CR3, CR4 [40]), several different families of Fc receptors have been characterized (50). These receptors include the high affinity $\mathrm{Fc} \gamma \mathrm{RI}$ found on mononuclear phagocytes and interferon- $\gamma$ stimulated neutrophils (51-53), the low affinity Fc $\gamma$ RII found on most lymphoid and myeloid cells including platelets (54), and FcrRIII, a low affinity receptor found on $M \phi$, neutrophils and natural killer cells (37). This latter receptor, which preferentially binds multivalent ligands, has been proposed as an Fc receptor that participates in IC binding. Indeed, previous data indicate a significant role for Fc $\gamma$ RIII in the handling of IgG-opsonized E (12). Accordingly, we investigated the role of FcrRIII in the handling of antibody/dsDNA
IC which fix $\mathrm{C}$ efficiently and engage $\mathrm{CR} 1$ (on E) rapidly and with high affinity.

\section{Role of Fc $\gamma$ RIII in IC clearance}

Infusion of anti-Fc $\gamma$ RIII MAb 3G8, both as intact IgG and as Fab fragments, induced a modest impairment in the clearance of E-bound model IC (Fig. $3 A$ and Fig. 5). More apparent was the effect on the handling of non-E-bound IC, which may have captured less $\mathrm{C} 3 \mathrm{~b}$ (Fig. 5). These observations indicated that blockade of the ligand binding site of Fc $\gamma$ RIII on fixed tissue $M \phi$ interfered with the uptake of model IC. However, these data could not distinguish between interference with initial engagement of the IC by the $\mathrm{M} \phi$ and impairment of retention of IC after initial engagement.

An approach to this question can be made using IC bound to $E$ in vitro to formulate the experimental framework (Fig. 6). One model of IC transfer would require rapid release of the IC from the E upon entry of the E-IC into the hepatic environment followed by engagement of the IC in a non-E-bound state by the M $\phi$ (Fig. $6 A$ ). However, no evidence for Factor I-mediated release of IC from $\mathrm{E}$ could be found in our experiments (Fig. $3 \mathrm{~B}$ ). If one assumes that the $\mathrm{M} \phi$ encounters the IC directly in the E-bound state (Fig. $6 \mathrm{~B}$ ) as suggested by the work of Robineaux more than 25 years ago (55), then rapid stripping would occur as a consequence of physical engagement of the E-IC by the M $\phi$. If blockade of Fc $\gamma$ RIII interferes with this engagement, the clearance of E-bound IC would be prolonged without the generation of stripped, non-E bound IC. If blockade of Fc $\gamma$ RIII did not interfere with engagement but did impair Fc receptor-mediated retention of the IC on the $M \phi$ cell surface, this would lead to stripped, non-E bound IC in the circulation. In order to examine this specific question, we looked for the appearance of TCA-precipitable and SASprecipitable IC (bound to $\mathrm{E}$ in vitro) in the circulation after MAb infusion (Fig. 3). At every time point, both when the preand posttreatment E IC clearance curves were superimposable and when they were divergent, significant levels of non-E bound $\mathrm{IC}_{1,500}$ appeared in the circulation after MAb 3G8 infusion. Given the "direct contact" model of transfer, it would appear that retention of the IC after stripping from the $E$ (and presumed chemical modification of the IC [29] and/or E-CR1 $[48,49])$ by the $M \phi$ is impaired by Fc receptor blockade. This postulated mechanism, which implies impaired retention and subsequent release of the IC, is reminiscent of the release reaction reported by Atkinson, Frank, and colleagues for sequestration and release of C-opsonized E (9). Of course, these considerations do not exclude participation of Fc receptors in initial engagement of the IC by the $\mathbf{M} \phi$ in either model.

The handling of soluble IC by $\mathbf{M} \phi$ appears to involve an intricate interaction between the IC and several different receptor systems. The equivalent binding of $\mathrm{IC}_{1,500}$ and $\mathrm{IC}_{500}$ to $\mathrm{CR} 1$ on chimp $\mathrm{E}$ and their unequal binding to and clearance by $\mathbf{M} \phi$ argues for significant qualitative differences in $\mathbf{M} \phi$ binding of IC compared to CR 1 -mediated $E$ binding of IC. The relative contribution to clearance of the IC by each receptor system will depend upon the specific immunochemical properties of the IC. For example, IC that fix $\mathrm{C}$ but do not capture sufficient $\mathrm{C} 3 \mathrm{~b}$ (27) will be handled more by Fc receptors. The number of expressed receptors, their spatial grouping (56) and their intrinsic properties (perhaps reflecting allelic polymorphisms; Salmon, J. E., J. C. Edberg, and R. P. Kimberly. Manuscript submitted for publication.) will also contrib- 
ute to the relative role of each system. Genetically determined differences in receptor structure $(57,58)$, expression $(59)$ and function $(60,61)$, and acquired differences in expression and display may be important in determining net function. For example, patients with SLE show both defects in C and Fc receptor dysfunction which can vary with disease activity (11, 62). Further understanding of all of the components of the IC transfer and uptake mechanism will provide the insight necessary to identify critical pathogenetic mechanisms and to potentially manipulate them to advantage.

\section{Acknowledgments}

We thank the staff at LEMSIP for assistance in performing the in vivo experiments and Ms. E. Wright (University of Virginia) for excellent technical assistance with the in vitro experiments. We also thank Dr. C. L. Christian for his continued support and Ms. P. B. Redecha for critically reviewing the manuscript.

This work was supported in part by grants AR-33062 (Dr. Kimberly), AI-24322 (Dr. Unkeless), and AR-24083 (Dr. Taylor) from the National Institutes of Health, the Irvington Institute for Medical Research (Dr. Edberg), and the New York Chapter of the Arthritis Foundation.

\section{References}

1. Haakenstad, A. O., and M. Mannik. 1974. Saturation of the reticuloendothelial system with soluble immune complexes. $J$. Immunol. 112:1939-1948.

2. Germuth, F. G. 1953. A comparative histologic and immunologic study in rabbits of induced hypersensitivity of the serum type. $J$. Exp. Med. 97:257-282.

3. Wilson, C. B., and F. J. Dixon. 1971. Quantification of acute and chronic serum sickness in the rabbit. J. Exp. Med. 134:7s-18s.

4. Haakenstad, A. O., and M. Mannik. 1975. The disappearance kinetics of soluble immune complexes prepared with reduced and alkylated antibodies and with intact antibodies in mice. Lab. Invest. 35:283-291.

5. Mannik, M. 1982. Pathophysiology of circulating immune complexes. Arthritis Rheum. 25:783-787.

6. Benacerraf, B., M. Sebestyen, and N. S. Cooper. 1959. The clearance of antigen-antibody complexes from the blood by the reticuloendothelial system. J. Immunol. 82:131-137.

7. Mannik, M., and W. P. Arend. 1971. Fate of preformed immune complexes in rabbits and rhesus monkeys. J. Exp. Med. 134:19s-31s.

8. Arend, W. P., and M. Mannik. 1971. Studies on antigen-antibody complexes. II. Quantification of tissue uptake of soluble complexes in normal and complement depleted rabbits. J. Immunol. 107:63-75.

9. Frank, M. M., A. D. Schreiber, J. P. Atkinson, and C. J. Jaffe. 1977. Pathophysiology of immune hemolytic anemia. Ann. Intern. Med. 87:210-222.

10. Frank, M. M., T. J. Lawley, M. I. Hamburger, and E. J. Brown. 1983. Immunoglobulin $\mathrm{G} \mathrm{Fc}$ receptor-mediated clearance in autoimmune diseases. Ann. Intern. Med. 98:206-218.

11. Kimberly, R. P., N. L. Meryhew, and O. A. Runquist. 1986. Mononuclear phagocyte function in SLE. I. Bipartite Fc- and complement-dependent dysfunction. J. Immunol. 137:91-96.

12. Clarkson, S. B., R. P. Kimberly, J. E. Valinsky, M. D. Witmer, J. B. Bussel, R. L. Nachman, and J. C. Unkeless. 1986. Blockade of clearance of immune complexes by an anti-Fc receptor monoclonal antibody. J. Exp. Med. 164:474-489.

13. Cornacoff, J. B., L. A. Hebert, W. L. Smead, M. E. VanAman, D. J. Birmingham, and F. J. Waxman. 1983. Primate erythrocyte immune complex-clearing mechanism. J. Clin. Invest. 71:236-247.

14. Waxman, F. J., L. A. Hebert, J. B. Cornacoff, M. E. VanAman,
W. L. Smead, E. H. Kraut, D. J. Birmingham, and J. M. Taguiam. 1984. Complement depletion accelerates the clearance of immune complexes from the circulation of primates. J. Clin. Invest. 74:13291340.

15. Waxman, F. J., L. A. Hebert, F. G. Cosio, W. L. Smead, M. E. VanAman, J. M. Taguaim, and D. J. Birmingham. 1986. Differential binding of immunoglobulin $A$ and immunoglobulin G1 immune complexes to primate erythrocytes in vivo: immunoglobulin A immune complexes bind less well to erythrocytes and are preferentially deposited in glomeruli. J. Clin. Invest. 77:82-89.

16. Cosio, F. G., L. A. Hebert, D. J. Birmingham, B. L. Dorval, A. P. Bakaletz, G. A. Kujala, J. C. Edberg, and R. P. Taylor. 1987. Clearance of human antibody/DNA immune complexes and free DNA from the circulation of the nonhuman primate. Clin. Immunol. Immunopathol. 42:1-9.

17. Paccaud, J. P., G. Steiger, A. G. Sjoholm, P. J. Spaeth, and J. A. Schifferli. 1987. Tetanus toxoid- anti-tetanus toxoid complexes: a potential model to study the human complement transport system for immune complex. Clin. Exp. Immunol. 69:468-476.

18. Schifferli, J. A., Y. C. Ng, J. Estreicher, and M. J. Walport. 1988. The clearance of tetanus/anti-tetanus toxoid immune complexes from the circulation of humans. J. Immunol. 140:899-904.

19. Edberg, J. C., G. A. Kujala, and R. P. Taylor. 1987. Rapid immune adherence reactivity of nascent soluble antibody/DNA immune complexes in the circulation. J. Immunol. 139:1240-1244.

20. Lobatto, S., M. R. Daha, A. A. Voetman, J. H. Evers-Schouten, A. A. van Es, E. K. J. Pauwels, and L. A. van Es. 1987. Clearance of soluble aggregates of human immunoglobulin $\mathrm{G}$ in healthy volunteers and chimpanzees. Clin. Exp. Immunol. 69:133-141.

21. Schifferli, J. A., Y. C. Ng, and D. K. Peters. 1986. The role of complement and its receptor in the elimination of immune complexes. N. Engl. J. Med. 315:488-495.

22. Walport, M. J., and P. J. Lachman. 1988. Erythrocyte complement receptor type 1 , immune complexes, and the rheumatic diseases. Arthritis Rheum. 31:153-158.

23. Miller, G. W., A. D. Steinberg, I. Green, and V. Nussenzweig. 1975. Complement dependent alterations in the handling of immune complexes by NZB/W mice. J. Immunol. 114:1166-1170.

24. Taylor, R. P., G. Kujala, K. Wilson, E. Wright, and A. Harbin. 1985. In vivo and in vitro studies of the binding of antibody/dsDNA immune complexes to rabbit and guinea-pig platelets. J. Immunol. 134:2250-2558.

25. Edberg, J. C., G. A. Kujala, and R. P. Taylor. 1987. Clearance kinetics and immunochemistry in rabbits of soluble antibody/DNA immune complexes. Effects of antibody class and DNA conformation. J. Immunol. 139:180-187.

26. Hebert, L. A., and F. G. Cosio. 1987. The erythrocyte-immune complex-glomerulonephritis connection in man. Kidney Int. 31:877885.

27. Edberg, J. C., L. Tosic, E. Wright, W. Sutherland, and R. P. Taylor. 1988. Quantitative analysis of the relationship between C3 consumption, $\mathrm{C} 3 \mathrm{~b}$ capture, and immune adherence of complementfixing antibody/DNA immune complexes. J. Immunol. 141:42584265.

28. Edberg, J. C., L. Tosic, and R. P. Taylor. 1989. Immune adherence and the processing of soluble complement-fixing antibody/DNA immune complexes in mice. Clin. Immunol. Immunopathol. 51:118132.

29. Medof, M. E., G. M. Prince, and J. J. F. Oger. 1982. Kinetics of interaction of immune complexes with complement receptors on human red blood cells. Modification of complexes during interaction with red cells. Clin. Exp. Immunol. 48:715-725.

30. Ng, Y. C., J. A. Schifferli, and M. J. Walport. 1988. Immune complexes and erythrocyte CR1 (complement receptor type 1): effect of CR1 numbers on binding and release reactions. Clin. Exp. Immunol. 71:481-485.

31. Horgan, C., J. Burge, L. Crawford, and R. P. Taylor. 1984. The kinetics of $\left[{ }^{3} \mathrm{H}\right] \mathrm{dsDNA} /$ anti-DNA immune complex formation, bind- 
ing by red blood cells, and release in serum: effect of DNA m.w. and conditions of antibody excess. J. Immunol. 133:2079-2084.

32. Tan, E. M., P. H. Schur, R. I. Carr, and H. G. Kunkel. 1966. Deoxyribonucleic acid (DNA) and antibodies to DNA in the serum of patients with SLE. J. Clin. Invest. 45:1732-1740.

33. Koffler, D. 1974. Immunopathogenesis of systemic lupus erythematosus. Annu. Rev. Med. 25:149-164.

34. Lennek, R., A. S. Baldwin, S. J. Waller, K. W. Morley, and R. P. Taylor. 1981. Studies on the physical biochemistry and complement-fixing properties of DNA/anti-DNA immune complexes. J. Immunol. 127:602-608.

35. Taylor, R. P., and C. Horgan. 1984. Quantitative determination of anti-dsDNA antibodies and antibody/dsDNA stoichiometries in prepared, soluble complement fixing antibody/dsDNA immune complexes. Mol. Immunol. 21:853-862.

36. Horgan, C., and R. P. Taylor. 1984. Studies on the kinetics of binding of complement-fixing dsDNA/anti-dsDNA immune complexes to the red blood cells of normal individuals and patients with systemic lupus erythematosus. Arthritis Rheum. 27:320-329.

37. Fleit, H. B., S. D. Wright, and J. C. Unkeless. 1982. Human neutrophil Fc receptor distribution and function. Proc. Natl. Acad. Sci. USA. 79:3275-3279.

38. Aarden, L. A., F. Lakmaker, and E. R. DeGroot. 1976. Immunology of DNA. IV. Quantitative aspects of the Farr assay. J. Immunol. Methods. 11:153-163.

39. Taylor, R. P., C. Horgan, M. Hooper, and J. Burge. 1985. Dynamics of interaction between complement-fixing antibody/ dsDNA immune complexes and erythrocytes. J. Clin. Invest. 75:102111.

40. Ross, G. D., and M. E. Medof. 1985. Membrane complement receptors specific for bound fragments of C3. Adv. Immunol. 37:217267.

41. Siegelman, J., H. B. Fleit, and N. S. Peress. 1987. Characterization of immunoglobulin G-Fc receptor activity in the outflow system of the cerebrospinal fluid. Cell Tissue Res. 248:599-605.

42. Nelson, R. A. 1953. The immune-adherence phenomenon: an immunological specific reaction between microorganisms and erythrocytes leading to enhanced phagocytosis. Science (Wash. DC) 118:733737.

43. Miyakawa, Y., A. Yamada, K. Kosaka, F. Tsuda, E. Kosugi, and M. Mayumi. 1981. Defective immune-adherence (C3b) receptor on erythrocytes from patients with systemic lupus erythematosus. Lancet. ii:493-497.

44. Iida, K., R. Mornaghi, and V. Nussenzweig. 1982. Complement receptor (CR1) deficiency in erythrocytes from patients with systemic lupus erythematosus. J. Exp. Med. 155:1427-1438.

45. Wilson, J. G., W. W. Wong, P. H. Schur, and D. T. Fearon. 1982. Mode of inheritance of decreased C3b receptors on erythrocytes of patients with systemic lupus erythematosus. N. Engl. J. Med. 307:981-986.

46. Taylor, R. P., C. Horgan, R. Buschbaker, C. M. Brunner, C. E. Hess, W. M. O'Brien, and H. J. Wanebo. 1983. Decreased complement mediated binding of antibody $/{ }^{3} \mathrm{H}$-dsDNA immune complexes to the red blood cells of patients with systemic lupus erythematosus, rheumatoid arthritis, and hematologic malignancies. Arthritis Rheum. 26:736-744.

47. Emlen, W., and M. Mannik. 1978. Kinetics and mechanisms for removal of circulating single-stranded DNA in mice. J. Exp. Med. 147:684-699.

48. Ross, G. D., W. J. Yount, M. J. Walport, J. B. Winfield, C. J. Parker, C. R. Fuller, R. P. Taylor, B. L. Myones, and P. J. Lachmann. 1985. Disease-associated loss of erythrocyte complement receptors (CR 1, C3b receptors) in patients with systemic lupus erythematosus and other diseases involving autoantibodies and/or complement activation. J. Immunol. 135:2005-2014.

49. Ripoche, J., and R. B. Sim. 1986. Loss of complement receptor type 1 (CR1) on ageing of erythrocytes. Studies of proteolytic release of the receptor. Biochem. J. 235:815-821.

50. Anderson, C. L., and R. J. Looney. 1986. Human leukocyte IgG Fc receptors. Immunol. Today. 7:264-266.

51. Anderson, C. L. 1982. Isolation of the receptor for IgG from a human monocyte cell line (U937) and from peripheral blood monocytes. J. Exp. Med. 156:1794-1805.

52. Perussia, B., E. T. Dayton, R. Lazarus, V. Fanning, and G. Trinchieri. 1983. Immune interferon induces the receptor for monomeric IgG on human monocytic and myeloid cells. J. Exp. Med. 158:1092-1113.

53. Petroni, K. C., L. Shen, and P. M. Guyre. 1988. Modulation of human polymorphonuclear leukocyte IgG Fc receptors and $\mathrm{Fc}$ receptor-mediated functions by IFN- $\gamma$ and glucocorticoids. J. Immunol. 140:3467-3472.

54. Looney, R. J., G. N. Abraham, and C. L. Anderson. 1986. Human monocytes and U937 cells bear two distinct Fc receptors for IgG. J. Immunol. 136:1641-1647.

55. Robineaux, R., and J. Pinet. 1960. An in vitro study of some mechanisms of antigen uptake by cells. Ciba Found. Symp. (Cellular Aspects of Immunity) 5-40.

56. Paccaud, J. P., J.-L. Carpentier, and J. A. Schifferli. 1988. Direct evidence for the clustered nature of complement receptors type I on the erythrocyte membrane. J. Immunol. 141:3889-3894.

57. Werner, G., A. E. G. Kr. von dem Borne, M. J. E. Bos, J. F. Tromp, C. M. van der Plas-van Dalen, F. J. Visseer, C. P. Engelfriet, and P. A. T. Tetteroo. 1986. Localization of the human NAl alloantigen on neutrophil Fc- $\gamma$-Receptors. In Leukocyte Typing II. Vol. 3. E. L. Reinherz, B. F. Haynes, L. M. Nadler, and I. D. Bernotein, editors. Springer Verlag, New York. 109-121.

58. Anderson, C. L., D. H. Ryan, R. J. Looney, and P. C. Leary. 1987. Structural polymorphism of the human monocyte 40 kilodalton Fc receptor. J. Immunol. 138:2254-2256.

59. Rosenfeld, S. I., D. H. Ryan, R. J. Looney, C. L. Anderson, G. N. Abraham, and J. P. Leddy. 1987. Human Fc $\gamma$ receptors: stable inter-donor variation in quantitative expression on platelets correlates with functional responses. J. Immunol. 138:2869-2873.

60. Kimberly, R. P., A. Gibofsky, J. E. Salmon, and M. Fotino. 1983. Impaired Fc-mediated mononuclear phagocyte system clearance in HLA-DR2 and MT1-positive healthy young adults. J. Exp. Med. 157:1698-1703.

61. Salmon, J. E., R. P. Kimberly, A. Gibofsky, and M. Fotino. 1986. Altered phagocytosis by monocytes from HLA-DR2 and DR3 positive healthy adults is $\mathrm{Fc}$-gamma receptor specific. J. Immunol. $136: 3625-3630$

62. Atkinson, J. P. 1986. Complement activation and complement receptors in systemic lupus erythematosus. Springer Semin. Immunopathol. 9:179-194. 